\title{
SHADED APERTURES AND BARTLET APERTURES FOR TWO LINE RESOLUTIONS ON APERTURE SHAPING
}

\author{
T. Kiran Kumar ${ }^{1 *}$, A. Narsaiah ${ }^{2}$, K.Vinod Kumar ${ }^{3}$, D. Karuna Sagar ${ }^{4}$. \\ ${ }^{* 1}$ Research Scholar,Department of Physics, Osmania University, Hyderabad - 500001. \\ email ID: kiranvenkat3@gmail.com \\ ${ }^{2}$ Research Scholar,Department of Physics, Osmania University, Hyderabad - 500001 \\ ${ }^{3}$ Research Scholar, Department of Physics, Osmania University, Hyderabad - 500001 \\ ${ }^{4}$ Professor, Department of Physics, Osmania University, Hyderabad - 500001
}

*Corresponding Author: -

Email ID: kiranvenkat3@gmail.com

\begin{abstract}
: -
Several criteria of resolution, e.g. Rayleigh Criterion, Sparrow Criterion etc. are used for assessment of two line resolution of unobscured imaging systems. The choice of particular criterion is usually dictated by the threshold contrast sensitivity of the detector used for the purpose. Annular apertures and Shrink apertures have a narrower central lobe in the Line spread function and therefore they are expected to provide improved two line resolution characteristics compared to their unobscured counterparts. The interrelationship between the dip in central intensity, degree of central obscuration and the least resolvable distance are studied in this paper.
\end{abstract}

Keywords: two-line resolution, sparrow, Rayleigh criterion etc. 


\section{THEORY:}

For a diffraction limited Airy system,

$$
\begin{array}{r}
f(x, 0)=1 \text {, and the two-line image intensity will be given } \\
\text { as } B_{I L}^{\prime}\left(u^{\prime}, v^{\prime}\right)=\left|2 \int_{0}^{1} \operatorname{Cos}\left\{2 \pi\left(u^{\prime}+u_{0}\right) x\right\} d x+2 c \int_{0}^{1} \operatorname{Cos}\left\{2 \pi\left(u^{\prime}-u_{0}\right) x\right\} d x\right|^{2}
\end{array}
$$

Substituting for

$$
f(x, 0)=\operatorname{Cos}^{\alpha}(1-\beta x)
$$

$$
\begin{aligned}
& B_{L L}^{\prime}\left(u^{\prime}, v^{\prime}\right)=\left|2 \int_{0}^{1} \operatorname{Cos}^{\alpha}(1-\beta x) \operatorname{Cos}\left\{2 \pi\left(u^{\prime}+u_{0}\right) x\right\} d x+2 c \int_{0}^{1} \operatorname{Cos}^{\alpha}(1-\beta x) \operatorname{Cos}\left\{2 \pi\left(u^{\prime}-u_{0}\right) x\right\} d x\right|^{2} \\
& B^{\prime}(Z)=\left|2 \int_{0}^{1} \operatorname{Cos}^{\alpha}(1-\beta x) \operatorname{Cos}\left\{2 \pi\left(u^{\prime}+u_{0}\right) x\right\} d x+2 c \int_{0}^{1} \operatorname{Cos}^{\alpha}(1-\beta x) \operatorname{Cos}\left\{2 \pi\left(u^{\prime}-u_{0}\right) x\right\} d x\right|^{2}
\end{aligned}
$$

Where ' $Z=2 \pi u^{\prime}$

In the case of annular apertures, the above equation is written as,

$$
B^{\prime}(Z)=\left|2 \int_{z}^{1} \operatorname{Cos}^{\alpha}(1-\beta x) \operatorname{Cos}\left\{2 \pi\left(u^{\prime}+u_{0}\right) x\right\} d x+2 c \int_{z}^{1} \operatorname{Cos}^{\alpha}(1-\beta x) \operatorname{Cos}\left\{2 \pi\left(u^{\prime}-u_{0}\right) x\right\} d x\right|^{2}
$$

where $\varepsilon$ is the central circular obscuration parameter $(0<\varepsilon<1)$.

Two line resolutions are defined for incoherent imaging as the ability to distinguish two bright lines having equal intensity. At the Sparrow resolution criterion the two lines are separated by a distance at which the intensity does not drop along a line connecting the two centers of the Line spread functions (LSF)

The image quality of an optical imaging system may be improved by improving its resolution capability. In an image forming system, resolution is a measure of the ability to separate images of two neighboring object lines. In the absence of aberrations, each line object would according to geometrical optics give rise to a sharp line image
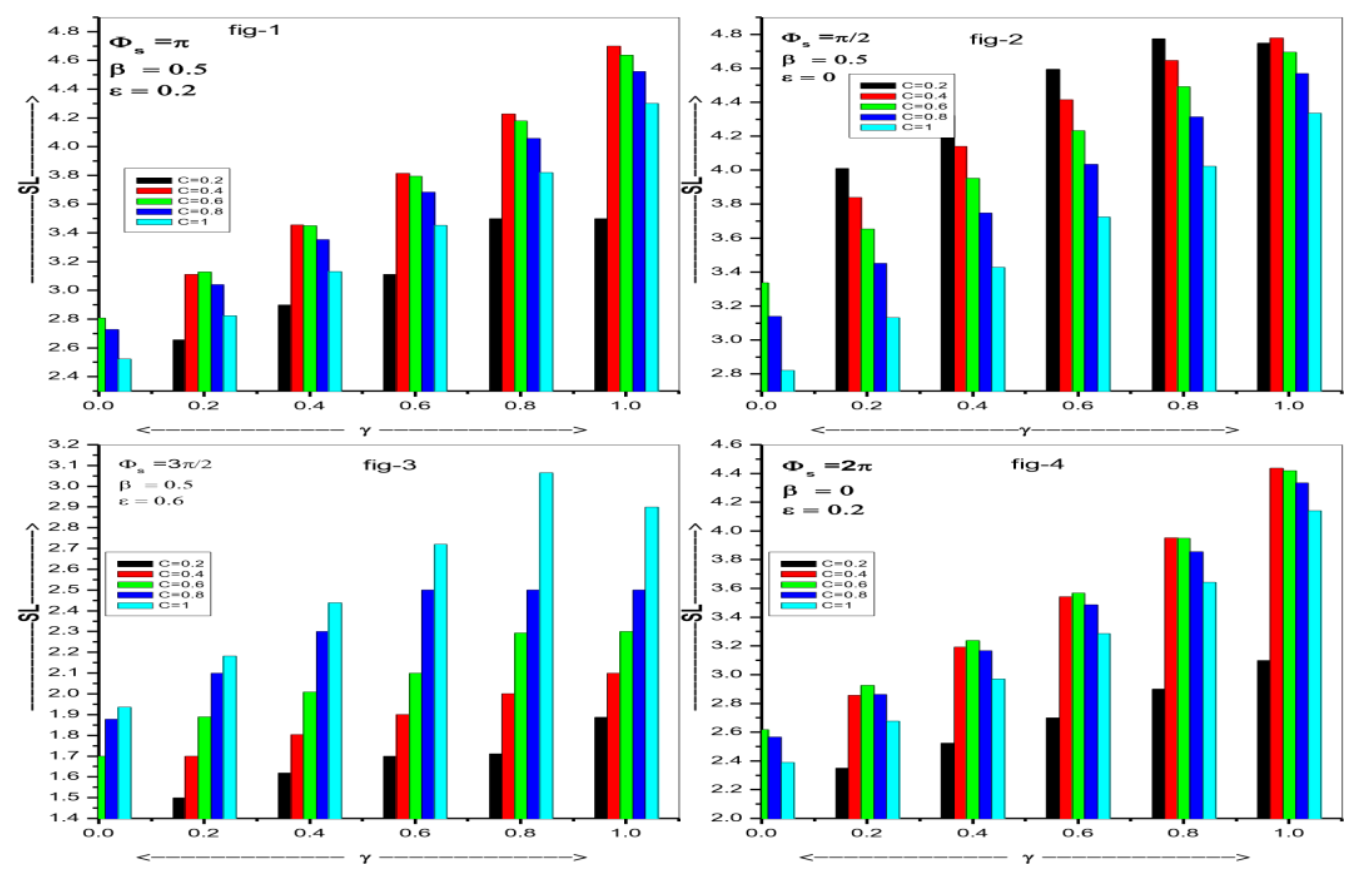

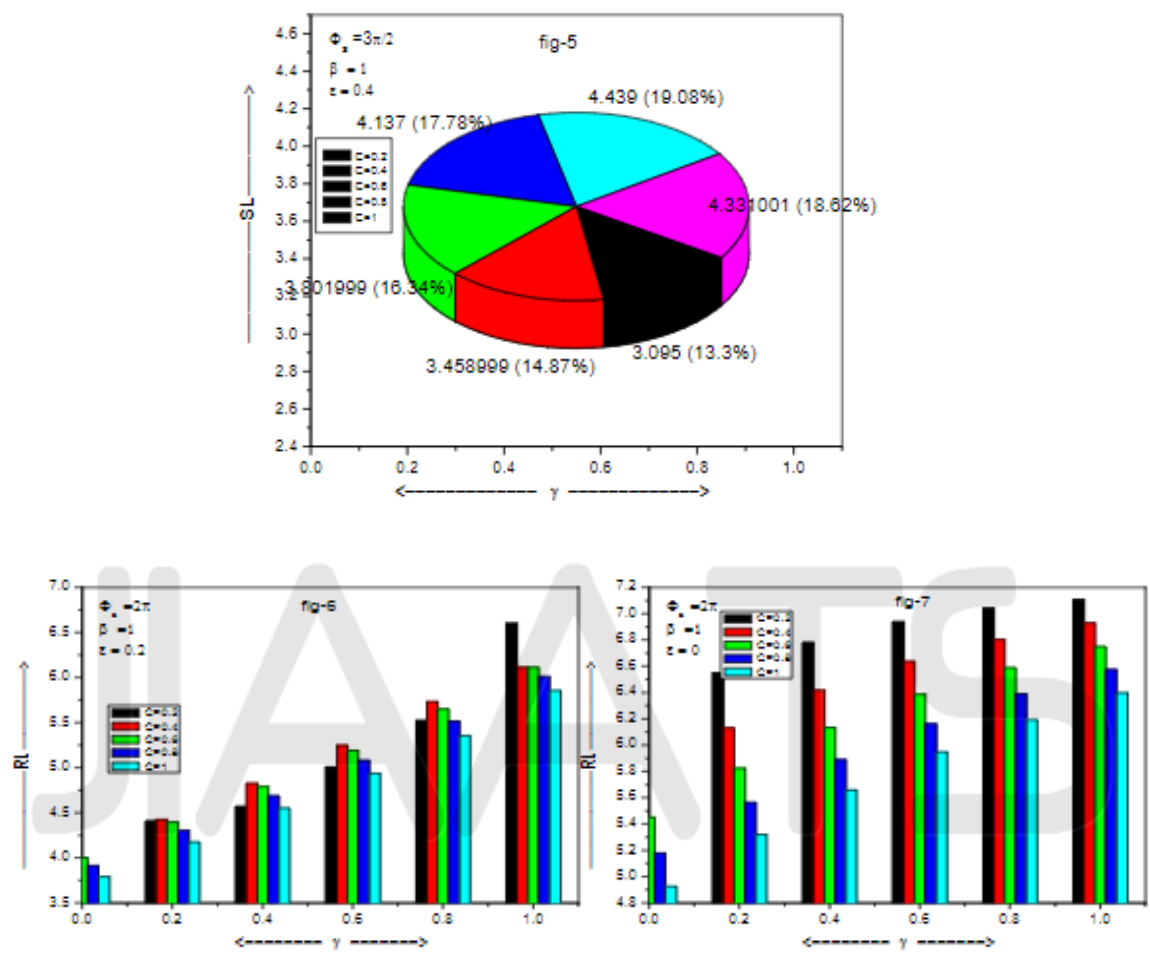

\section{Results and Discussions:}

The Rayleigh and the Sparrow limits of resolution for various values of the parameters, for the Bartlett filter and Hanning amplitude filter are presented in the above figures. The limits of resolution for the super-resolver are also given in the same figures are compared. The Rayleigh and Sparrow limits of resolution are minimum for the unapodised circular aperture (Airy pupil), resolution under severe apodisation when two equally bright object lines are in incoherent illumination and these are, respectively, 3.832 and 2.980. These limits are maximum for partially apodised $(\beta=1.0)$ circular aperture, operating in coherent illumination when the object points are of widely different intensities $(c=0.20)$. These values are respectively 7.298 (R.L) and 6.655 (S.L). The corresponding Rayleigh and Sparrow limits of resolution for the different filter are lower than those for the apodisers. It is also clear that the limits of resolution general, increased in fig 6 at $\mathrm{c}=0.2$ and at coherence $\gamma=1$ there we got the maximum RL value i.e. at the aperture is annularing $(\varepsilon=0.2)$ in fig -5 on the application spherical aberration for the annular apertures $(\varepsilon=0.4)$ all the sparrow limit values are in between $13 \%$ to $19 \%$.

This we observed in the case of Shaded and Bartlet apertures.

\section{REFERENCES:}

[1].Resolution Of Two Point Objects With Primary Spherical Aberration Under Incoherent Illumination IJIRS -.K.Vinod Kumar,D Karuna Sagar.,R.Sayanna. September, 2013 Vol 2 Issue 9

[2].K.Surendar, Ph.D. Thesis, Osmania University, Hyderabad, India, 1993

[3].C.J.R. Sheppard and A. Choudhury, "Annular Pupils, Radial Polarization, and Superresolution,”Appl. Opt. 43(22), $4322-4327$ (2004).

[4].Mallat, S., Zhong, S.: Characterization of signals from multiscale edges. IEEE Transactions on pattern analysis and machine intelligence 14 (1992) $710\{732$

[5].A.C. Assafrao, A.J.H. Wachters, S.F. Pereira, and H.P. Urbach, "Influence of the Numerical Aperture on the Superresolved InSb Focused Spot,” Jpn. J. Appl. Phys. 51, 112,501 (2012).

[6].I. Hwang, J. Kim, J. Bae, H. Kim, D. Yoon, I. Park, and D. Shin, "Improvement of Nois Characteristics in SuperResolution Near-Field Structure Disc,” Jpn. J. Appl. Phys. 44(5B), 3542-3546 (2005). 